\title{
Oral hydration in children with cerebral palsy
}

\author{
Maria Teresa Botti Rodrigues Santos ${ }^{1}$, Maria Cristina Duarte Ferreira ${ }^{2}$, \\ Renata Oliveira Guaré ${ }^{1}$, Oliver A. Nascimento ${ }^{3}$, Jose R. Jardim ${ }^{3}$ \\ ${ }^{1}$ Universidade Cruzeiro do Sul - UNICSUL, School of Dentistry, Area of Pediatric, São Paulo, SP, Brazil \\ ${ }^{2}$ Serviço Nacional de Aprendizagem Comercial - SENAC, Area of Pediatric, São Paulo, SP, Brazil \\ ${ }^{3}$ Universidade Federal de São Paulo - UNIFESP, Paulista School of Medicine, Respiratory Division, São Paulo, SP, Brazil
}

Received for publication: April 07, 2014 Accepted: June 10, 2014

Correspondence to: Maria Teresa Botti Rodrigues Santos Universidade Cruzeiro do Sul Rua Constantino de Souza, 454, apto 141 CEP: 04605-001 - São Paulo - SP - Brasil Phone: +55 11999722301 - Fax: +55 1150930865

E-mail: drsantosmt@yahoo.com.br

\section{Abstract}

Salivary osmolality reflects the hydration status of individuals with cerebral palsy necessary for adequate unstimulated salivary flow rate. Aim: To investigate whether oral motor performance is determinant for the hydration status and the effect of a supplemental oral fluid supply on salivary osmolality. Methods: The sample consisted of 99 children with cerebral palsy aged 6 to 13 years old. In this study, children participated in 2-day evaluations: $1^{\text {st }}$ day - baseline: saliva collection, caries experience and oral motor performance evaluations; and $2^{\text {nd }}$ day: saliva collection after supplemental fluid supply. Prior to each evaluation, the participants were trained for saliva collection. Unstimulated whole saliva was collected using cotton roll at baseline, with the amount of fluid usually offered by caregivers, and $48 \mathrm{~h}$ after baseline, with as much as twice the normal daily fluid intake previously offered. Salivary osmolality was measured using a freezing point depression osmometer. Caries experience index for decayed, missed and filled teeth (DMFT) was evaluated. According to the Oral Motor Assessment Scale, the children were classified into subfunctional or functional groups. Chi-square, Student's t test and Pearson's correlation coefficient were used. Results: The subfunctional group presented a higher percentage of quadriplegic children $(p<0.001)$, with significantly higher values for caries experience $(p<0.001)$ and salivary osmolality $(p<0.001)$, which did not diminish when supplemental fluid supply was offered, compared with the functional group $(p=0.001)$. Conclusions: The effectiveness of oral motor performance plays an important role in the hydration status of children with cerebral palsy and those with worse oral motor performance may be at higher risk of oral diseases.

Keywords: cerebral palsy; motor skills disorders; muscle spasticity; osmolar concentration; fluid therapy.

\section{Introduction}

Cerebral palsy describes a group of chronic disorders that involve movement and posture development, often accompanied by epilepsy, secondary musculoskeletal problems and disturbances of sensation, perception, cognition, communication and behavior. It is the most common cause of severe physical disability in childhood ${ }^{1}$, with an estimated prevalence of 2.4 per 1000 children $^{2}$.

Alterations in mastication and swallowing in children with cerebral palsy result in feeding dysfunctions that may lead to reduced dietary intake, prolonged feeding times and poor nutritional status accompanied by compromised physical performance $e^{3-7}$.

Children with cerebral palsy present low unstimulated salivary flow rate, $\mathrm{pH}$ and buffer capacity ${ }^{8}$, and variations in the activity of enzymes and sialic acid concentrations9. It has also been reported that children with cerebral palsy present increased salivary osmolality and total protein concentration ${ }^{10}$, together with increased salivary, urine and plasma osmolalities, characterizing an impaired 
hydration status ${ }^{11}$. Decreased levels of hydration (dehydration) may cause diminished salivary output ${ }^{12}$, which could compromise the protective function exerted by saliva and increase the risk of oral diseases ${ }^{11}$.

Considering that an adequate fluid intake and homeostasis of total body water is essential for human health and survival, the aims of this study were to investigate whether (i) oral motor performance is determinant for hydration status and (ii) the effect of a supplemental oral fluid supply on salivary osmolality in children with cerebral palsy. The tested hypothesis was that compromised oral motor performance interferes in fluid intake, resulting in a diminished health status for these children.

\section{Material and methods}

\section{Participants}

Ninety-nine non-institutionalized male and female children (aged 6 to 13 years-old) with a medical diagnosis of spastic cerebral palsy ${ }^{13}$, who were referred to a specialized rehabilitation center in São Paulo, SP, Brazil, were consecutively included in this study. The adults responsible for each child provided written informed consent to participate in the study, which was approved by the Cruzeiro do Sul University Review Board for Human Studies (\#0152/2011). Children using any drug that could interfere with saliva secretion (anticholinergic, neuroleptic and benzodiazepine drugs) for at least $72 \mathrm{~h}$ prior to examination or with a history of head and neck radiation or surgical procedures to reduce drooling were excluded from the study. Demographic and clinical data, including sex, age and Gross Motor Function Classification System ${ }^{14}$, were obtained for all children.

Children participated in 2-day evaluations: $1^{\text {st }}$ day baseline saliva collection, caries experience and oral motor performance evaluations; and $2^{\text {nd }}$ day - saliva collection after supplemental fluid supply. Prior to each evaluation, the participants were trained for saliva collection.

\section{Saliva collection and assessment}

The caregivers were carefully instructed to record the total amount of fluid (water, milk, juice, soda, soup) offered to their children in the $48 \mathrm{~h}$ prior to the first saliva collection (baseline). After the first saliva collection, caregivers were instructed to maintain the same intake for the children and to offer a supplemental volume of fluid (as much as twice the normal daily fluid intake) for the following $48 \mathrm{~h}$. Then, a new saliva sample was collected (supplemental volume supply).

At least $2 \mathrm{~h}$ after the previous meal, unstimulated whole saliva was collected by a single calibrated examiner between 8:00 and 9:00 a.m., using the absorbent method ${ }^{15}$. After the mouth was dried with sterile gauze, one absorbent cotton roll (Salivette ${ }^{\circ}$; Sarstedt, Nümbrecht, Germany) was placed in the mouth under the tongue for exactly $5 \mathrm{~min}$, with the children comfortably seated in a ventilated and illuminated room. Immediately after, the saliva collection sample was frozen in dry ice, transported to the laboratory and stored at $-80{ }^{\circ} \mathrm{C}$ until analysis. Salivary osmolality was measured using a freezing point depression osmometer (Model Vapro Vapor Pressure Osmometer 5600; New Instrument, Washington, DC, USA).

\section{Caries experience}

Dental clinical evaluation was performed by a single calibrated examiner under standardized conditions, using optimal artificial lighting, compressed air to dry the teeth, a plane buccal mirror and a WHO probe. Caries experience was recorded according to the World Health Organization criteria $^{16}$, and decayed, missed and filled teeth were evaluated using the dmf-t / DMF-T index for primary and permanent dentition, respectively. In children with mixed dentition, dmf$\mathrm{t}$ and DMF-T were recorded together.

\section{Oral motor performance}

The same trained oral health care professional evaluated the performance of the masticatory muscles of all participants using the Oral Motor Assessment Scale ${ }^{17}$. The Kappa coefficient was used to evaluate the intra-rater consistency of the test-retest measurements. The significance level was set at $\mathrm{p}<0.05$ and the Kappa value for the final score was 1.00 .

The Oral Motor Assessment Scale was applied according to the following description. Three types of food were offered to the child: paste (Danonin ${ }^{\circledR}$ brand "petit Suisse" cheese), solid ("waffle" style cracker), and water in a cup with a straw. The child was asked to eat normally. The researcher observed the child's oral motor ability and indicated a score for each of the following items: mandibular closing, labial sealing with the utensil, anterior lingual sealing when swallowing, control of solid food when swallowing, suction with a straw, control of liquid when swallowing, and chewing.

The researcher did not guide or modify the way in which the caregiver helped or how the child ate. In cases in which the child exhibited more than one type of oral motor function for the same item, the most frequent behavior during the evaluation was determined. The final classification score for motor ability was determined based on the most frequent score. A score of 0 indicated the greatest degree of impairment (passive), 1 indicated subfunctional impairment, 2 indicated semi-functional impairment, and 3 indicated normal function, meeting efficiency standards. Children defined as having a final predominance type of passive and subfunctional (severely and moderately compromised oral motor performance) were classified into a single group that was named the subfunctional group, while the semi-functional and functional individuals (slightly and very slightly compromised oral motor performance) were named the functional group.

\section{Statistical methods}

Statistical analyses were performed using the Statistical Package for Sciences (version 19.0; SPSS Inc., Chicago, IL, USA). To evaluate proportional differences between the studied groups, the Chi square test was used. The Student $t$ test was used to verify the hypothesis of equality between 
the two groups. Pearson's correlation coefficient was used to associate the behavior among the studied variables. The power of this sample was calculated using descriptive statistics of mean and standard deviation of saliva osmolarity collected at baseline, using a confidence interval of $95 \%$. A p value of 0.05 was the criterion for significance. Values are presented as means $\pm \mathrm{SD}$.

\section{Results}

The power of the sample of 99 children who participated in this study was 0.837 . The subfunctional $(n=49)$ and functional $(\mathrm{n}=50)$ groups did not differ regarding sex $(p=0.366)$ and age $(p=0.621)$. However, the subfunctional group presented a higher percentage of quadriplegic children $(p<0.001)$, with level V of the Gross Motor Function Classification System $(p<0.001)$. Regarding caries experience, the subfunctional group presented significantly higher dmf-t/DMF-T values $(p<0.001)$ (Table 1).

In relation to salivary osmolality, the subfunctional group presented significantly higher values $(p<0.001)$ not only at baseline, but also when the supplemental fluid supply was offered compared with the functional group. Concerning the supplemental fluid supply, both groups showed an increased volume (subfunctional: $46.7 \pm 121.4 \mathrm{~mL}$; functional: $112.1 \pm 138.1 \mathrm{~mL})$ in the follow-up period. Despite this fact, only the functional group showed reduction in salivary osmolality. For the subfunctional group, no effects on salivary osmolality were observed following supplemental fluid supply.
Figure 1 shows the values of the Pearson correlation coefficient for salivary osmolality and fluid supply values. Salivary osmolality was negatively correlated with fluid supply at baseline $(\mathrm{p}<0.001$; A) and after 48 h $(\mathrm{p}<0.001 ; \mathrm{B})$.

\section{Discussion}

Understanding the impact of oral motor dysfunction in children with cerebral palsy may be helpful in identifying individuals at high risk of developing oral diseases. To our knowledge, this is the first study to evaluate the effect of a supplemental fluid supply on salivary osmolality in children with spastic cerebral palsy. Analysis of these results confirm the hypothesis of this study, that is, compromised oral motor performance interferes in fluid intake, resulting in increased salivary osmolality and suggesting that greater neurological impairment causes the diminished hydration status.

Clinically, cerebral palsy varies in severity and extremely diverse levels of functional independence can be observed in individuals with the same medical diagnosis, due to the extent of neurodevelopmental disorder ${ }^{1,18}$. Spastic cerebral palsy is by far the most common type of movement disorder in cerebral palsy, occurring in $70 \%$ to $80 \%$ of all cases ${ }^{1}$. Regarding oral motor performance, spastic cerebral palsy children from the subfunctional group were more severely compromised, represented by the quadriplegic clinical pattern and Gross Motor Function Classification System level V.

Salivary osmolality has been described as a reliable parameter of hydration status and reflects changes in plasma

Table 1. Descriptive characteristics of children with cerebral palsy classified into subfunctional and functional groups.

\begin{tabular}{|c|c|c|c|c|}
\hline \multirow[b]{2}{*}{ Variables } & \multicolumn{4}{|c|}{ Groups } \\
\hline & $\begin{array}{l}\text { Total } \\
(n=99)\end{array}$ & $\begin{array}{l}\text { Subfunctional } \\
\qquad(n=49)\end{array}$ & $\begin{array}{l}\text { Functional } \\
\qquad(n=50)\end{array}$ & Significance \\
\hline \multicolumn{5}{|l|}{ Sex, n (\%) } \\
\hline Female & $39(39.4)$ & $22(44.9)$ & $17(34.0)$ & $0.366^{a}$ \\
\hline Male & $60(60.6)$ & $27(55.1)$ & $33(66.0)$ & \\
\hline Age years (mean \pm SD) & $9.6 \pm 2.4$ & $9.8 \pm 2.6$ & $9.5 \pm 2.2$ & $0.621^{b}$ \\
\hline Clinical pattern, n (\%) & & & & $<0.001^{\star a}$ \\
\hline Quadriplegic & $50(50.5)$ & $38(77.5)$ & $12(24.0)$ & \\
\hline Diplegic & $40(40.4)$ & $11(22.5)$ & $29(58.0)$ & \\
\hline Hemiplegic & $9(9.1)$ & $0(0)$ & $9(18.0)$ & \\
\hline GMFCS, n (\%) & & & & $<0.001^{\star a}$ \\
\hline I & $9(9.1)$ & $0(0)$ & $9(18.0)$ & \\
\hline$\|$ & $9(9.1)$ & $0(0)$ & $9(18.0)$ & \\
\hline III & $7(7.1)$ & $1(2.1)$ & $6(12.0)$ & \\
\hline IV & $52(52.5)$ & $28(57.1)$ & $24(48.0)$ & \\
\hline V & $22(22.2)$ & $20(40.8)$ & $2(4.0)$ & \\
\hline Caries experience & $2.1 \pm 1.8$ & $3.5 \pm 1.4$ & $0.7 \pm 0.3$ & $<0.001^{* b}$ \\
\hline
\end{tabular}

${ }^{\mathrm{C} G M F C S}$ (Gross Motor Function Classification System) levels ${ }^{13}$ : I indicates walking without restrictions with limitations in more advanced gross motor skills; II indicates walking without assistive devices with limitations walking outdoors and in the community; III indicates walking with assistive mobility devices with limitations walking outdoors and in the community; IV indicates self-mobility with limitations, the patient is transported or uses powered mobility outdoors and in the community; $V$ indicates that self-mobility is severely limited even with assistive technology.

The data were compared with the following: a. Chi square test, b. Student t test, ${ }^{*} p<0.05$ 

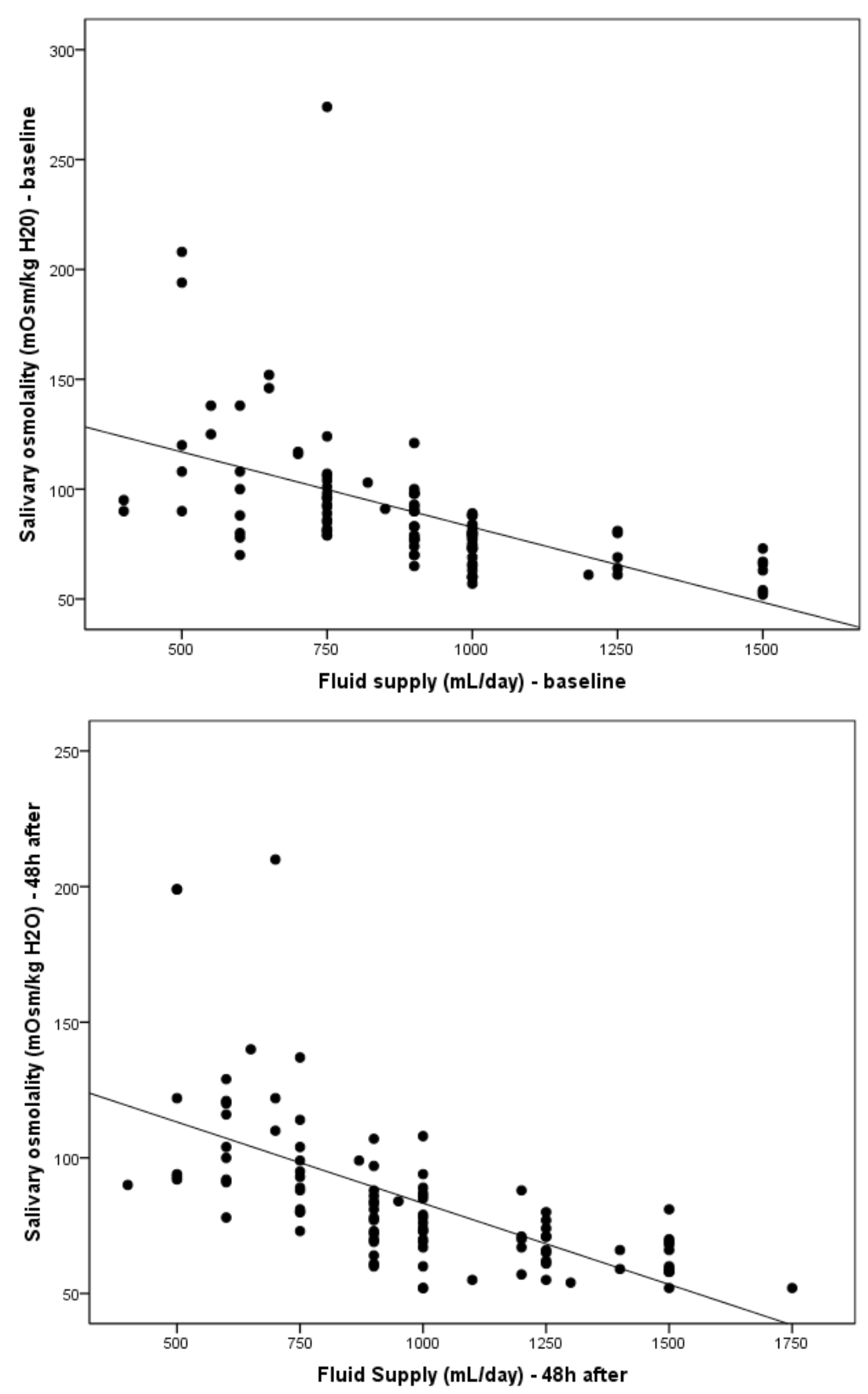

Fig.1. Illustration of Pearson's correlation between salivary osmolality and fluid supply values for baseline $(A)$ and after $48 \mathrm{~h}(\mathrm{~B})(\mathrm{R}=$ Pearson's correlation coefficient, $p<0.001)$.

Table 2. Salivary osmolality $\left(\mathrm{mOsm} / \mathrm{kg} \mathrm{H} \mathrm{H}_{2} \mathrm{O}\right)$ before and after supplemental fluid supply in children with spastic cerebral palsy classified into subfunctional and functional groups.

\begin{tabular}{lccc}
\hline $\begin{array}{l}\text { Variables } \\
\text { Baseline }\end{array} \quad \begin{array}{c}\text { Subfunctional } \\
(n=49)\end{array}$ & $\begin{array}{c}\text { Functional } \\
(n=50)\end{array}$ & Significance \\
$\quad$ Osmolality (mOsml) & $106.3 \pm 37.4$ & $74.3 \pm 11.7$ & $<0.001^{*}$ \\
$\quad \begin{array}{l}\text { Supplemental fluid supply } \\
\text { Osmolality (mOsml) }\end{array}$ & $101.1 \pm 32.7$ & $67.5 \pm 12.1$ & $<0.001^{*}$ \\
\hline The data were compared by the Student $t$ test. ${ }^{*} p<0.05$ &
\end{tabular}

and urine osmolality in cerebral palsy individuals ${ }^{11}$. The higher salivary osmolality observed in the spastic cerebral palsy children with subfunctional oral motor performance is very similar to the osmolality presented by individuals in dehydration conditions ${ }^{19}$.

In this study, analysis of the initial observations revealed that there is a causal relationship between the events of hydration and oral dysfunction. The reduction in salivary osmolality in the subfunctional and functional groups following supplemental fluid supply was $4.3 \%$ and $9.6 \%$, 
respectively. Patients in the most compromised group (subfunctional) drank less fluid $(6.7 \%)$ than those in the functional group (12.3\%).

The issue of hydration status and fluid diet intake in individuals with cerebral palsy has been rarely described in the literature ${ }^{10-11}$. Solid and semisolid food consistencies provide greater proprioceptive mouth stimulus, which facilitates the control of swallowing. In individuals with cerebral palsy who cannot sustain lip closure, the liquid diet intake usually flows out of the mouth, resulting in a lack of negative pressure for swallowing, which may cause choking. In individuals with cerebral palsy, water intake is generally below the required standards ${ }^{20}$ and the management of solid alimentary bolus is easier than liquid ingestion; on the other hand, small liquid boluses are more easily swallowed than large liquid boluses. Moreover, these individuals tend to consume small volume of liquids ${ }^{21}$. The total daily fluid supply recorded by caregivers from the functional group, was similar to those described in children with severe cerebral palsy ${ }^{20}$.

One limitation of this study was the fact that the volume supply was not fixed, since cerebral palsy children present difficulties in swallowing, although a higher fluid intake was observed during the observational period.

It is also relevant to this discussion to emphasize that, in this study, the severely oromotor compromised cerebral palsy individuals presented higher values of the caries experience index for both dentitions ${ }^{22-24}$, with higher prevalence of untreated caries ${ }^{25}$, which is in agreement with the literature ${ }^{26-27}$. In addition, the presence of pathological oral reflex of tonic bite ${ }^{4}$ makes tooth brushing, biofilm control and dental floss use more difficult, which directly impacts on oral hygiene ${ }^{27}$.

Further studies should assess the effectiveness of supplying a high liquid content with different consistencies to cerebral palsy children with severe oral motor compromise, since this may eventually help reducing salivary osmolality, increase salivary flow rate, improve oral hydration and reduce oral diseases. The findings of the present study suggest that oral motor performance is determinant for hydration status in cerebral palsy children and the most compromised individuals present a higher salivary osmolality, which is associated with an inadequate fluid intake.

\section{Acknowledgements}

This study was supported by the Fundação de Amparo a Pesquisa do Estado de São Paulo, FAPESP - process no.11/ 12475-8).

\section{References}

1. Richards $\mathrm{CL}$, Malouin F. Cerebral palsy: definition, assessment and rehabilitation. Handb Clin Neurol. 2013; 111: 183-95.

2. Hirtz D, Thurman DJ, Gwinn-Hardy K, Mohamed M, Chaudhuri AR, Zalutsky R. How common are the "common" neurologic disorders? Neurology. 2007; 68: 326-37.
3. Calis EA, Veugelers R, Rieken R, Tibboel D, Evenhuis HM, Penning C. Energy intake does not correlate with nutritional state in children with severe generalized cerebral palsy and intellectual disability. Clin Nut. 2010; 29: 617-21.

4. Dos Santos MT, Nogueira ML. Infantile reflexes and their effects on dental caries and oral hygiene in cerebral palsy individuals. J Oral Rehabil. 2005; 32: 880-5.

5. Fung EB, Samson-Fang L, Stallings VA, Conaway M, Liptak G, Henderson $\mathrm{RC}$, et al. Feeding dysfunction is associated with poor growth and health status in children with cerebral palsy. J Am Diet Assoc. 2002; 102: 361-73.

6. Sullivan PB. Gastrointestinal disorders in children with neurodevelopmental disabilities. Dev Disabil Res Rev. 2008; 14: 128-36.

7. Troughton KE, Hill AE. Relation between objectively measured feeding competence and nutrition in children with cerebral palsy. Dev Med Child Neurol. 2001; 43: 187-90.

8. Santos MT, Guaré R, Leite M, Ferreira MC, Nicolau J. Does the neuromotor abnormality type affect the salivary parameters in individuals with cerebral palsy? J Oral Pathol Med. 2010; 39: 770-4.

9. Rodrigues Santos MT, Siqueira WL, Nicolau J. Amylase and peroxidise activities and sialic acid concentration in saliva of adolescents with cerebral palsy. Quintessence Int. 2007; 38: 467-72.

10. Santos MT, Guaré RO, Leite MF, Ferreira MC, Durão MS, Jardim JR. Salivary osmolality in individuals with cerebral palsy. Arch Oral Biol. 2010; 55: 855-60.

11. Santos MT, Batista R, Guaré RO, Leite MF, Ferreira MC, Durão MS, et al. Salivary osmolality and hydration status in children with cerebral palsy. J Oral Pathol Med. 2011; 40: 582-6.

12. Amstrong LE. Assessing hydration status: the elusive gold standard. J Am Coll Nutr. 2007; 6: 575S-84S.

13. World Health Organization. 10th International Classification of Diseases and Related Health Problems, ICD-10, 2010. [cited 2014 Apr 10]. Available from: http://www.who.int/classifications/icd/en .

14. Palisano RJ, Rosenbaum $P$, Bartlett D, Livingston MH. Content validity of the expanded and revised Gross Motor Function Classification System. Dev Med Child Neurol. 2008; 50: 744-50.

15. Rotteveel LJ, Jongerius PH, van Limbeek J, van den Hoogen FJ. Salivation in healthy schoolchildren. Int J Pediatr Otorhinolaryngol. 2004; 68: 767-74.

16. World Health Organization. Oral health surveys: basic methods. 5th ed. Geneva: WHO; 2013.

17. Ortega Ade O, Ciamponi AL, Mendes FM, Santos MT. Assessment scale of the oral motor performance of children and adolescents with neurological damages. J Oral Rehabil. 2009; 36: 653-9.

18. Bax MC, Flodmark O, Tydeman C. Definition and classification of cerebral palsy. From syndrome toward disease. Dev Med Child Neurol Suppl. 2007; 109: 39-41.

19. Walsh NP, Laing SJ, Oliver SJ, Montague JC, Walters R, Bilzon JL. Saliva parameters as potential indices of hydration status during acute dehydration. Med Sci Sports Exerc. 2004; 36: 1535-42.

20. Veugelers R, Benninga MA, Calis EA, Willemsen SP, Evenhuis $H$, Tibboel $\mathrm{D}$, et al. Prevalence and clinical presentation of constipation in children with severe generalized cerebral palsy. Dev Med Child Neurol. 2010; 52: e216-21.

21. Andrew MJ, Parr JR, Sullivan PB. Feeding difficulties in children with cerebral palsy. Arch Dis Child Educ Pract Ed. 2012; 97: 222-9.

22. Ferreira de Camargo MA, Frias AC, Antunes JL. The incidence of dental caries in children and adolescents who have cerebral palsy and are participating in a dental program in Brazil. Spec Care Dentist. 2011; 31: 210-5.

23. Moreira RN, Alcântara CE, Mota-Veloso I, Marinho SA, Ramos-Jorge $\mathrm{ML}$, Oliveira-Ferreira F. Does intellectual disability affect the development of dental caries in patients with cerebral palsy? Res Dev Disabil. 2012; 33: 1503-7.

24. Santos MT, Biancardi M, Guare RO, Jardim JR. Caries prevalence in patients with cerebral palsy and the burden of caring for them. Spec Care Dentist. 2010; 30: 206-10. 
25. De Camargo MA, Antunes JL. Untreated dental caries in children with cerebral palsy in the Brazilian context. Int J Paediatr Dent. 2008; 18: 131-8.

26. Rodrigues dos Santos MT, Bianccardi M, Celiberti P, de Oliveira Guaré R. Dental caries in cerebral palsied individuals and their caregivers' quality of life. Child Care Health Dev. 2009; 35: 475-81.

27. Santos MT, Guare RO, Celiberti P, Siqueira WL. Caries experience in individuals with cerebral palsy in relation to oromotor dysfunction and dietary consistency. Spec Care Dentist. 2009; 29: 198-203. 